\title{
Implementing ACL Injury Prevention in Daily Sports Practice-It's Not Just the Program: Let's Build Together, Involve the Context, and Improve the Content
}

\author{
Anne Benjaminse ${ }^{1,3} \cdot$ Evert Verhagen $^{2}$
}

Accepted: 4 September 2021 / Published online: 17 September 2021

(c) The Author(s) 2021

\begin{abstract}
Although the benefits of current anterior cruciate ligament (ACL) injury prevention programmes have been demonstrated in efficacy studies, they, unfortunately, have had limited public health impact to date. For example, the incidence of ACL injuries continues to rise in adolescent athletes. Raising awareness and educating coaches and athletes is not enough to facilitate the widespread, sustained use of these programmes in the real-world setting. Considering the profound burden of ACL injuries, it is necessary to continue to improve the current ACL injury prevention programmes through co-creation. First, the uptake of the programmes should be optimized by a better appreciation and understanding of the individual, socio-cultural and environmental context (i.e., community). Second, the content of the programmes should be optimized to better reflect the demands of the sport by creating more ownership and increasing motivation (incorporating challenging, sport-specific and fun elements) with the end-users. In addition, implicit motor learning, random practice and differential learning are concepts that should be integrated when practising to obtain the most optimal results when learning or finetuning skills.
\end{abstract}

\section{Key Points}

Considering the profound burden of ACL injuries, it is necessary to continue to improve the current ACL injury prevention programs through co-creation with the endusers.

The context of the player and the demands of the sport (content) should be included when designing ACL injury prevention programs.

Motor learning methods that induce high practice variability to guide a player's search for his/her optimal movement solution are promising and warranted.

Anne Benjaminse

a.benjaminse@umcg.nl

1 Department of Human Movement Sciences, University of Groningen, UMC Groningen, Antonius Deusinglaan 1, 9713 AV Groningen, The Netherlands

2 Department of Public and Occupational Health, Amsterdam Collaboration on Health and Safety in Sports, Amsterdam Movement Sciences, Amsterdam UMC, University Medical Centres-Vrije Universiteit Amsterdam, Amsterdam, The Netherlands

3 School of Sport Studies, Hanze University Groningen, Groningen, The Netherlands

\section{Introduction}

Engaging in sport is one way of being physically active, and sports participation has a great positive influence on the level of health-enhancing physical activity and mental well-being $[1,2]$. Despite the health benefits of sports activities, sports injury and fear of (re-)injury are real barriers to sport participation. The risk of sports injuries substantially increases during youth, peaking in the 15- to 19-years age group [3]. Injuries may affect the athlete's career and their daily-life activities. One reason for nonparticipation in and drop-out from sports is sports-related injuries [4, 5]. Knee and ankle injuries in particular contribute to this problem [6]. One severe knee injury with increasing incidence is the anterior cruciate ligament (ACL) tear, which, in many cases, requires surgical intervention [6]. Per year, over two million ACL injuries occur worldwide. The majority of these injuries are observed in paediatric and adolescent athletes [6-10], with a higher incidence in girls compared to boys, especially at younger ages [11-13]. These ACL injuries lead to the longest withdrawal time from youth sports. Only $44 \%$ of these young athletes return to their pre-injury level of sports, and up to $23 \%$ sustain a re-injury, with many of them dropping out of sports entirely [14]. An ACL rupture is a devastating injury for a soccer player, resulting in the longest layoff 
times [15] and a reduced career length [16]. This change in life immensely affects both physical and psychosocial well-being in the short and long term. An ACL injury is associated with an increased risk of physical health issues: decreased sport participation [14], decreased physical activity [17] and increased body mass index (BMI) [18], high risk of subsequent knee injuries [19], and early-onset knee osteoarthritis [20]. The seriousness and severity of the ACL injury are reflected in the intensive, extended physical rehabilitation process that is essential for an optimal outcome [15]. The psychosocial impact of such a long recovery process can be particularly devastating. A lack of mobility may result in post-traumatic stress, depression, fear of re-injury, social isolation [21, 22], mood disturbances, anger [23], decreased locus of control, lowered self-efficacy or loss of self-worth as a result of not being able to perform pre-injury state functions [24, 25]. Thus, many health benefits are lost due to injuries, negatively affecting a healthy lifestyle and public health. Health gains associated with sports and physical activities need to be optimised by ensuring appropriate and efficacious preventative interventions are in place. Much effort has been invested on preventing ACL injuries, for example the potential reduction of (non-contact) ACL injuries can be up to $67 \%$ in females in controlled settings [26]. However, with regard to effectiveness, ACL injury rates have not decreased over recent decades in the real world [27]. To bridge this gap, we should bring context to the exercises. On the one hand, we can do this by developing ACL injury-prevention programmes and stakeholders as a shared responsibility. On the other hand, we should look more at the demands of the sports and how to optimally teach these exercises (content).

\section{Why Aren't Efficacious Anterior Cruciate Ligament $(A C L)$ Injury-Prevention Programmes Adopted?}

Many ACL injury-prevention programmes provide coaches and sports teams with warm-up exercises [28-30]. Even though showing promising efficacy results, unfortunately the programmes are not well implemented in real-world settings [31-33], often because they do not match specific contexts $[34,35]$. Often, coaches experience these exercises as being too static and not sport-specific, insufficiently supporting their performance goals, insufficiently challenging the athlete, and not being tailored to the individual athlete [31]. Implementation in the real-world setting therefore remains a major challenge [36]. Because of these barriers, the exercises are not experienced as being attractive and applicable [31,37], and only a few coaches are actually using the exercises, leading to less optimal effectiveness than was expected from controlled research [28-30]. Lack of uptake and maintenance of such programmes are thus of ongoing concern, and adoption, fidelity and maintenance are challenging [38]. Implementation efforts focus on singular, static exercises for the end-users (coaches, athletes) without considering individual contextual situations leading to tailor-made solutions [39]. For the durability of these ACL injury-prevention programmes and for them to be effective in the real world, it is necessary to design them taking the real world into account in terms of better considering both the context and the programmes' content.

\section{Now What?}

\subsection{Context}

It is time to listen to and recognise coaches' needs, barriers, knowledge and ideas, and promote a co-learning and empowering process between the scientific and practical fields [39]. Implementation needs to be made sustainable, and exercises must be created jointly by theoretical and practical experts. The sports medicine research field still approaches solutions with a linear tame problem approach (i.e., implying that one optimal solution exists) $[34,40]$. However, preventing sports injuries poses a socalled wicked problem (i.e., implying multiple solutions exist) [41] and is not amenable to top-down general solutions. This implies that multiple optimal solutions exist, depending on the setting, such as level and type of sports, club culture and coach's knowledge. Suppose we consider sports injuries a wicked, complex phenomenon [42, 43] and ACL injury prevention as a complex system. In that case, it requires multiple stakeholders working together and sharing the responsibility to prevent injuries. Systems thinking helps us understand how the elements related to ACL injury and its prevention are under the control of different stakeholders [44]. These different stakeholders (e.g., coaches, sports physiotherapists, parents, club administrators, and regional and national federation administrators) relate to the athlete at different levels, that is, individual, socio-cultural and environmental levels [45]. Therefore, to develop more comprehensive ACL injury-prevention strategies, ideally all stakeholders should be involved from the beginning by acknowledging how their roles potentially impact injury and its prevention [44, 46]. If end-users are not engaged initially, their knowledge and experience are not implemented to their full potential, and exercises are often modified because they do not match their context $[31,37]$. Delivering programme content supported by a context-specific and evidence-informed implementation 
plan leads to greater implementation activity, which is important for injury reduction [31].

ACL injury-prevention efforts need to be built around coaching behaviours to be effective. If not, this will lead to the development of context-free preventive solutions. ACL injury prevention should focus on 'what works for whom, when, where, and why' [47]. Consequently, there is a need to know and understand more about the behavioural aspects related to ACL injury occurrence. Thus, contextual factors should be considered early on in the development of ACL injury prevention intervention and not just in the implementation phase. One important example of doing so is considering the coach to be central in their context (i.e., human-centred design) and engaging them to understand their preferences [48]. This user-centredness and design thinking prioritises a deep empathy for the desires, needs and challenges of end-users to fully understand a problem and develop more comprehensive and effective solutions [49]. Design thinking promotes opposing ideas and debate (divergent), and aims to uncover what is important to consumers in their everyday lives. Therefore, the co-creation process with coaches is a non-linear process that requires a comprehensive understanding of underlying problems and follows theoretical demands. This process starts with the coaches, involving them in the creation process, for example through pilots and consolidations (i.e., cyclical and iterative intervention development and evaluation process) [39]. It should include mapping of current barriers and beliefs, their alignment, and development of content through discussion, consensus meetings and practical validations, all involving the end-users. The process ends with interventions that are tailor-made to suit context-specific needs [50]. A focus on implementation is, therefore, critical to influence behaviour change and give coaches ownership. Engaging coaches to understand their knowledge, ideas, wishes, needs and preferences is crucial for reaching sustainable, evidenceinformed injury-prevention practice [44]. The exact process of co-creation depends on the context. For example, how in-depth the input from coaches along the process will be, will depend on availability, level of sport and education, experience, etc. The golden rule is to design a programme with their input and with their agreement. When developing ACL injury-prevention programmes, the focus should be set on the necessity of sustainable implementation through applicability in the real-world setting.

\subsection{Content}

Exercises should ideally be fun, sport-specific, challenging and individualised. This will enhance both the athlete's and the coach's satisfaction with the programme [31], and improves motor learning [51]. A non-contact ACL injury results from a failure of the system to effectively self-organise movements within the quickly changing constraints present. Current ACL injury-prevention exercises do not reflect the neurocognitive and physical demands of ball-team sports [52] as learning traditional, closed-skill anticipated exercises could not account for this continuous changing environment during a game in which injuries typically occur and where the athletes have to move and perform optimally. Therefore, the ability to perform pre-planned movement tasks is poor preparation for the dynamic, responsive and unplanned motor tasks that occur in sports. It is time now to take the complex and unpredictable sports environment into account when learning adaptive motor skills. Situational awareness, arousal and attentional resources of the individual affect the complex integration of vestibular, visual and somatosensory information needed for neuromuscular control [53]. The impact of the quickly changing environment, and the athlete's ability to perceive and interpret this and select an appropriate motor response can thus not be ignored when ACL injury reduction is the goal. In other words, neurocognitive skills such as visual attention, processing speed and dual tasking (lower-order), and inhibition, working memory and cognitive flexibility (core) impact lower extremity biomechanics [54]. Exercises should thus also account for practising these neurocognitive skills in combination with the motor task $[51,55]$.

It is good to search for the best practice conditions that engage the learner in an effortful learning process and have been shown to enhance retention and transfer [56]. For retention (i.e., long-term effectiveness) and transfer of skills to occur, incorporating the key concepts for practice outlined below may be more effective in preventing injuries [57-59]. First, implicit motor learning (such as, among others, analogy learning, the external focus of attention) and motivation, stimulated by (a) self-controlled learning (enhancing feelings of autonomy) and (b) enhanced expectancies (enhancing feelings of competence and self-efficacy) [60], should be considered.

\subsubsection{Optimal Motor Learning-Implicit Learning}

Implicit learning methods aim to minimise declarative (explicit) knowledge about movement execution during learning. For this purpose, implicit learning can be induced by providing external focus instructions or analogies rather than explicit instructions during motor skill acquisition. Implicit learning reduces the reliance on the working memory and promotes more of an automatic process [61]. It is for this reason that it can be more effective in more complex tasks. Competitive sports can be psychologically demanding, and decision-making accuracy deteriorates in athletes under pressure, involving increased task complexity [62]. Implicit motor learning has been shown to be more sustainable in situations with physical [63-65] or mental pressure 
$[66,67]$, which is very relevant to the sports context. For example, applying implicit motor learning when practising optimising agility movements could be asking the athlete to 'pretend your knees are headlights and point them towards the new direction' (analogy instruction) [68] or 'when turning, push yourself as forcefully as possible from the ground' (external focus instruction) [69] to enhance movement form in the frontal and sagittal planes, respectively.

\subsubsection{Optimal Motor Learning-Motivation}

Learning is a problem-solving process, and the athlete's involvement during practice to search for his or her own (movement) solutions enhances learning. Having some choice appeals to one of the basic psychological needs of human beings and enhances intrinsic motivation [59]. Having some choice can stimulate beliefs in one's capabilities (competence) and enhance feelings of self-efficacy, for example choosing the variety of the exercises the athlete thinks s/he can do best or that challenged him or her most. Experiencing the exercises to be challenging and sport-specific makes them meaningful and will give a motivational boost. In summary, it has been demonstrated that motivation is crucial to improve motor skill learning [60]. Human motivation is dependent on (the perception of) one's actions having effects on the environment [70]. Positive expectations for the near future (feelings of 'yes I can do this'), as well as perceptions of autonomy, are intrinsic to motivation [60]. Circumstances that enhance learners' expectations and confidence for future performance success enhance movement automaticity and improve motor learning [71]. Even if the effects of one's actions are trivial, intrinsic motivation is enhanced if the person has control over those effects [70]. Conditions that provide an opportunity for choice may be motivating because they indicate control over upcoming events. Therefore, it is advised that coaches try to stimulate the players' enjoyment, needs satisfaction, or sense of challenge or curiosity during the activity [59]. For example, when practising an agility manoeuvre, the coach can give the players a choice about which variation of the task to practice (e.g., practising the task with different materials or practising the task at different difficulty levels). Another way to provide feelings of autonomy is by asking questions: "How can you make this exercise more challenging for yourself?" or "Let me know when you're ready to move to the next level of this exercise". Also, the use of non-controlling language means the avoidance of words such as 'should,' 'must' and 'have to' to convey a sense of choice or flexibility [72].

\subsubsection{Training Design}

While performing a movement, team sports players have to quickly visually perceive their action opportunities and those of opponents and teammates. These continuous actions are performed under time pressure as movement possibilities emerge and disappear. Therefore, a non-contact ACL injury is the result of a series of self-organised movements that emerge from the interaction with quickly changing constraints. This means an injurious movement is not produced by an isolated player but emerges from a dynamically varying association between the player's characteristics, the stimulus-rich environment and the desired actions [73-76]. Considering this ecological dynamics approach, presenting players with varying game-like variables so that the elicited movement is more reflective of the movements in injury scenarios may be beneficial. Random practice or differential learning may be options to do this.

Random practice (i.e. practising multiple skills in random order with high contextual interference) while adding various constraints should be considered for improving motor learning [51, 58]. The absence of the consecutive repetition of a given skill during a random execution sequence leads to poorer direct performance than does experiencing a sequence in blocks [77]. However, the poor direct performance levels of those who practice in a random order mask the greater psychophysiological demands of subcortical structures that this type of condition requires. This increased participation during the practice by brain regions involved in motor skill planning and execution [78], which is reflected by a higher activation level and cortical excitability, is a critical factor in learning consolidation [57]. The opposite effect is observed in retention testing, during which random practice leads to decreased activation levels in the indicated regions [57], leading to greater automaticity of movement. The variable practice involves performing variations of the task or completely different tasks throughout a training session [57]. This means, for example, mixing unanticipated deceleration and cutting in different directions, jumping and single-leg landing on the left and right leg, with and without the ball, from different angles, at different speeds, etc.

Lastly, differential learning can be considered to enhance motor learning. Differential learning means that players randomly perform various movement patterns when practising a skill (rather than only practising the supposedly 'correct' movement form). They are stimulated to engage in a selforganised learning process [79]. This can be done by adding a task or environmental constraints that 'force' them to execute the same task differently. For example, passing a football or tennis ball while cutting; cutting while juggling with a tennis ball; having teammates throw or pass balls at the player; having the opponent defend while doing an agility parkour; performing some single leg hops, a turn or a funny jump before cutting; performing cuts on sand, asphalt, within a limited space, etc. The coach should be creative and make it fun for the players. The purpose is to develop control over the body's many degrees of freedom, and have 
adaptable movement solutions available, rather than training for the 'ideal' movement technique, limiting movement solutions for variable tasks.

Future research is needed to evaluate the effectiveness of such proposed elements in ACL injury-prevention programmes. However, motor learning methods that induce great practice variability to guide a player's search for his/ her optimal movement solution are promising and warranted [80].

\section{Conclusion}

We do not have the programme; we are not there yet. Including coaches and co-creating (context) and adopting motor learning principles (content) may help improve ACL injury-prevention implementation. For programmes to be more effective, they should also better reflect the sporting demands. If people do not use the available programmes, the programmes are not good enough. In addition, future efforts should focus on the enhancement of current programmes as well as successful implementation through leadership, management and education

\section{Declarations}

Funding No sources of funding were used to assist in the preparation of this article.

Conflicts of interest Anne Benjaminse and Evert Verhagen declare that they have no conflicts of interest relevant to the content of this article.

Additional declarations for articles in life science journals that report the results of studies involving humans and/or animals Not applicable.

Ethics approval Not applicable.

Consent to participate Not applicable.

Consent for publication All authors provided consent for publication.

Availability of data and material Not applicable.

Code availability Not applicable.

Author contributions Both authors contributed equally to the manuscript and read and approved the final version.

Open Access This article is licensed under a Creative Commons Attribution 4.0 International License, which permits use, sharing, adaptation, distribution and reproduction in any medium or format, as long as you give appropriate credit to the original author(s) and the source, provide a link to the Creative Commons licence, and indicate if changes were made. The images or other third party material in this article are included in the article's Creative Commons licence, unless indicated otherwise in a credit line to the material. If material is not included in the article's Creative Commons licence and your intended use is not permitted by statutory regulation or exceeds the permitted use, you will need to obtain permission directly from the copyright holder. To view a copy of this licence, visit http://creativecommons.org/licenses/by/4.0/.

\section{References}

1. DiPietro L, Al-Ansari SS, Biddle SJH, et al. Advancing the global physical activity agenda: recommendations for future research by the 2020 WHO physical activity and sedentary behavior guidelines development group. Int J Behav Nutr Phys Act. 2020;17:143. https://doi.org/10.1186/s12966-020-01042-2.

2. Penedo FJ, Dahn JR. Exercise and well-being: a review of mental and physical health benefits associated with physical activity. Curr Opin Psychiatry. 2005;18:189-93. https://doi.org/10.1097/00001 504-200503000-00013.

3. EuroSafe, Injuries in the European Union, Summary on injury statistics 2012-2014. 2016: Vienna.

4. Indriðadóttir MH, Sveinsson $\mathrm{P}$, Magnússon KP, Arngrímsson SÁ, Jóhannsson E. Prevalence of sport injuries, sport participation and drop out due to injury in young adults. Laeknabladid. 2015;101:451-6. https://doi.org/10.17992/lbl.2015.10.45.

5. Steffen K, Engebretsen L. More data needed on injury risk among young elite athletes. Br J Sports Med. 2010;44:485-9. https://doi. org/10.1136/bjsm.2010.073833.

6. Beck NA, Lawrence JTR, Nordin JD, et al. ACL tears in school-aged children and adolescents over 20 years. Pediatrics. 2017;139:e20161877.

7. Fabricant PD, Kocher MS. Anterior cruciate ligament injuries in children and adolescents. Orthop Clin N Am. 2016;47:777-88.

8. Hootman JM, Dick R, Agel J. Epidemiology of collegiate injuries for 15 sports: summary and recommendations for injury prevention initiatives. J Athl Train. 2007;2:311-9.

9. Nogaro MC, Abram SGF, Alvand A, Bottomley N, Jackson WFM, Price A. Paediatric and adolescent anterior cruciate ligament reconstruction surgery. Bone Joint J. 2020.102-B:239-245. https://doi.org/10.1302/0301-620X.102B2.

10. Werner BC, Yang S, Looney AM, Gwathmey FW Jr. Trends in pediatric and adolescent anterior cruciate ligament injury and reconstruction. J Pediatr Orthop. 2016;36:447-52.

11. Agel J, Rockwood T, Klossner D. Collegiate ACL injury rates across 15 sports: national collegiate athletic association injury surveillance system data update (2004-2005 through 2012-2013). Clin J Sport Med. 2016;26:518-23. https://doi.org/10.1097/JSM 0000000000000290.

12. Beck NA, Lawrence JTR, Nordin JD, DeFor TA, Tompkins M. ACL tears in school-aged children and adolescents over 20 years. Pediatrics. 2017;139: e20161877. https://doi.org/10.1542/peds. 2016-1877.

13. Weitz FK, Sillanpää PJ, Mattila VM. The incidence of paediatric ACL injury is increasing in Finland. Knee Surg Sports Traumatol Arthrosc. 2020;28:363-8. https://doi.org/10.1007/ s00167-019-05553-9.

14. Ardern CL, Webster KE, Taylor NF, Feller JA. Return to sport following anterior cruciate ligament reconstruction surgery: a systematic review and meta-analysis of the state of play. Br J Sports Med. 2011;45:596-606. https://doi.org/10.1136/bjsm. 2010.076364

15. Dingenen B, Gokeler A. Optimization of the return-to-sport paradigm after anterior cruciate ligament reconstruction: a critical 
step back to move forward. Sports Med. 2017;47:1487-500. https://doi.org/10.1007/s40279-017-0674-6.

16. Niederer D, Engeroff T, Wilke J, Vogt L, Banzer W. Return to play, performance, and career duration after anterior cruciate ligament rupture: a case-control study in the five biggest football nations in Europe. Scand J Med Sci Sports. 2018;28:222633. https://doi.org/10.1111/sms.13245.

17. Kuenze C, Collins K, Pfeiffer KA, Lisee C. Assessing physical activity after ACL injury: moving beyond return to sport. Sports Health. 2021;29:19417381211025308. https://doi.org/10.1177/ 19417381211025307.

18. MacAlpine EM, Talwar D, Storey EP, Doroshow SM, Lawrence JTR. Weight gain after ACL reconstruction in pediatric and adolescent patients. Sports Health. 2020;12:29-35. https://doi. org/10.1177/1941738119870192.

19. Wiggins AJ, Grandhi RK, Schneider DK, Stanfield D, Webster KE, Myer GD. Risk of secondary injury in younger athletes after anterior cruciate ligament reconstruction: a systematic review and meta-analysis. Am J Sports Med. 2016;44:1861-76. https://doi.org/10.1177/0363546515621554.

20. von Porat A, Roos EM, Roos H. High prevalence of osteoarthritis 14 years after an anterior cruciate ligament tear in male soccer players: a study of radiographic and patient relevant outcomes. Ann Rheum Dis. 2004;63:269-73. https://doi.org/10. 1136/ard.2003.008136.

21. Ardern CL, Taylor NF, Feller JA, Webster KE. A systematic review of the psychological factors associated with returning to sport following injury. Br J Sports Med. 2013;47:1120-6. https://doi.org/10.1136/bjsports-2012-091203.

22. McArdle S. Psychological rehabilitation from anterior cruciate ligament-medial collateral ligament reconstructive surgery: a case study. Sports Health. 2010;2:73-7. https://doi.org/10.1177/ 1941738109357173.

23. Morrey MA, Stuart MJ, Smith AM, Wiese-Bjornstal DM. A longitudinal examination of athletes' emotional and cognitive responses to anterior cruciate ligament injury. Clin J Sport Med. 1999;9:63-9.

24. Flanigan DC, Everhart JS, Glassman AH. Psychological factors affecting rehabilitation and outcomes following elective orthopaedic surgery. J Am Acad Orthop Surg. 2015;23:563-70.

25. te Wierike SC, van der Sluis A, van den Akker-Scheek I, Elferink-Gemser MT, Visscher C. Psychosocial factors influencing the recovery of athletes with anterior cruciate ligament injury: a systematic review. Scand J Med Sci Sports. 2013;23:527-40. https://doi.org/10.1111/sms.12010.

26. Webster KE, Hewett TE. Meta-analysis of meta-analyses of anterior cruciate ligament injury reduction training programmes. J Orthop Res. 2018;36:2696-708. https://doi.org/10. 1002/jor.24043.

27. Gokeler A, Benjaminse A, Seil R, Kerkhoffs G, Verhagen E. Using motor learning principles to enhance ACL injury prevention programmes. Sports Orthop Traumatol. 2018;34:23-30. https://doi.org/10.1016/j.orthtr.2017.12.006.

28. Bizzini M, Dvorak J. FIFA 11+: an effective programme to prevent football injuries in various player groups worldwide-a narrative review. Br J Sports Med. 2015;49:577-9.

29. Mandelbaum BR, Silvers HJ, Watanabe DS, Knarr JF, Thomas SD, Griffin LY, Kirkendall DT, Garrett W Jr. Effectiveness of a neuromuscular and proprioceptive training program in preventing anterior cruciate ligament injuries in female athletes: 2-year follow-up. Am J Sports Med. 2005;33:1003-10. https://doi.org/ $10.1177 / 0363546504272261$

30. Waldén M, Atroshi I, Magnusson H, Wagner P, Hägglund M. Prevention of acute knee injuries in adolescent female football players: cluster randomised controlled trial. BMJ. 2012;344: e3042. https://doi.org/10.1136/bmj.e3042.
31. Donaldson A, Callaghan A, Bizzini M, Jowett A, Keyzer P, Nicholson M. A concept mapping approach to identifying the barriers to implementing an evidence-based sports injury prevention programme. Inj Prev. 2019;25:244-51. https://doi.org/10.1136/ injuryprev-2017-042639.

32. Lindblom H, Waldén M, Carlfjord S, Hägglund M. Implementation of a neuromuscular training programme in female adolescent football: 3-year follow-up study after a randomised controlled trial. Br J Sports Med. 2014;48:1425-30. https://doi.org/10.1136/ bjsports-2013-093298.

33. Norcross MF, Johnson ST, Bovbjerg VE, Koester MC, Hoffman MA. Factors influencing high school coaches' adoption of injury prevention programmes. J Sci Med Sport. 2016;19:299-304. https://doi.org/10.1016/j.jsams.2015.03.009.

34. Finch C. A new framework for research leading to sports injury prevention. J Sci Med Sport. 2006;9:3-9. https://doi.org/10. 1016/j.jsams.2006.02.009.

35. Donaldson A, Finch CF. Planning for implementation and translation: seek first to understand the end-users' perspectives. $\mathrm{Br}$ J Sports Med. 2012;46:306-7. https://doi.org/10.1136/bjspo rts-2011-090461.

36. Verhagen E, Finch CF. Setting our minds to implementation. $\mathrm{Br}$ J Sports Med. 2011;45:1015-6. https://doi.org/10.1136/bjspo rts-2011-090485.

37. O'Brien J, Finch CF. Injury prevention exercise programmes for professional soccer: understanding the perceptions of the end-users. Clin J Sport Med. 2017. 27:1-9. 10.1097JSM.0000000000000291.

38. Bruder AM, Crossley KM, Mosler AB, Patterson B, Haberfield M, Donaldson A. Co-creation of a sport-specific anterior cruciate ligament injury risk reduction program for women: a concept mapping approach. J Sci Med Sport. 2020;23:353-60. https://doi. org/10.1016/j.jsams.2019.10.019.

39. Tee JC, McLaren SJ, Jones B. Sports injury prevention is complex: we need to invest in better processes, not singular solutions. Sports Med. 2020;50:689-702. https://doi.org/10.1007/ s40279-019-01232-4.

40. van Mechelen W, Hlobil H, Kemper HC. Incidence, severity, aetiology and prevention of sports injuries. A review of concepts. Sports Med. 1992;14:82-99.

41. Camillus C. Strategy as a wicked problem. Harvard Bus Rev. 2008. 1-10.

42. Bekker $\mathrm{S}$, Paliadelis P, Finch CF. The translation of sports injury prevention and safety promotion knowledge: insights from key intermediary organisations. Health Res Policy Syst. 2017;15:25. https://doi.org/10.1186/s12961-017-0189-5.

43. Bittencourt NFN, Meeuwisse WH, Mendonça LD, Nettel-Aguirre A, Ocarino JM, Fonseca ST. Complex systems approach for sports injuries: moving from risk factor identification to injury pattern recognition-narrative review and new concept. Br J Sports Med. 2016;50:1309-14. https://doi.org/10.1136/bjsports-2015-095850 ((epub 2016 Jul 21)).

44. Bolling C, van Mechelen W, Pasman HR, Verhagen E. Context matters: revisiting the first step of the "sequence of prevention" of sports injuries. Sports Med. 2018;48:2227-34. https://doi.org/ 10.1007/s40279-018-0953-x.

45. Ageberg E, Bunke S, Lucander K, Nilsen P, Donaldson A. Facilitators to support the implementation of injury prevention training in youth handball: a concept mapping approach. Scand J Med Sci Sports. 2019;29:275-85. https://doi.org/10.1111/sms. 13323.

46. Bolling C, Mellette J, Pasman HR, van Mechelen W, Verhagen E. From the safety net to the injury prevention web: applying systems thinking to unravel injury prevention challenges and opportunities in Cirque du Soleil. BMJ Open Sport Exerc Med. 2019;5: e000492. https://doi.org/10.1136/bmjsem-2018-000492. 
47. Bekker S, Clark AM. Bringing complexity to sports injury prevention research: from simplification to explanation. Br J Sports Med. 2016;50:1489-90.

48. Bazzano AN, Martin J, Hicks E, Faughnan M, Murphy L. Human-centred design in global health: a scoping review of applications and contexts. PLoS ONE. 2017;1(12): e0186744. https://doi.org/10.1371/journal.pone.0186744.

49. Roberts JP, Fisher TR, Trowbridge MJ, Bent C. A design thinking framework for healthcare management and innovation. Healthcare. 2016;4:11-4. https://doi.org/10.1016/j.hjdsi.2015. 12.002 .

50. Verhagen E, Voogt N, Bruinsma A, Finch CF. A knowledge transfer scheme to bridge the gap between science and practice: an integration of existing research frameworks into a tool for practice. Br J Sports Med. 2014;48:698-701.

51. Gokeler A, Neuhaus D, Benjaminse A, Grooms DR, Baumeister J. Principles of motor learning to support neuroplasticity after ACL injury: implications for optimizing performance and reducing risk of second ACL injury. Sports Med. 2019;49:85365. https://doi.org/10.1007/s40279-019-01058-0.

52. Swanik CB. Brains and sprains: the brain's role in noncontact anterior cruciate ligament injuries. J Athl Train. 2015;50:11002. https://doi.org/10.4085/1062-6050-50.10.08.

53. Swanik CB, Covassin T, Stearne DJ, Schatz P. The relationship between neurocognitive function and noncontact anterior cruciate ligament injuries. Am J Sports Med. 2007;35:943-8. https:// doi.org/10.1177/0363546507299532.

54. Gokeler A, Benjaminse A, Della Villa F, Tosarelli F, Verhagen E, Baumeister J. Anterior cruciate ligament injury mechanisms through a neurocognition lens: implications for injury screening. BMJ Open Sport Exerc Med. 2021;17(7): e001091. https:// doi.org/10.1136/bmjsem-2021-001091.

55. Piskin D, Benjaminse A, Dimitrakis P, Gokeler A. Neurocognitive and neurophysiological functions related to ACL injury: a framework for neurocognitive approaches in rehabilitation and return-to-sports tests. Sports Health. 2021;8:19417381211029264. https://doi.org/10.1177/19417 381211029265 .

56. Bjork RA. Creating desirable difficulties to enhance learning. Carmarthen: Crown House Publishing; 2017.

57. Lage GM, Ugrinowitsch H, Apolinário-Souza T, Vieira MM, Albuquerque MR, Benda RN. Repetition and variation in motor practice: a review of neural correlates. Neurosci Biobehav Rev. 2015;57:132-41. https://doi.org/10.1016/j.neubiorev.2015.08. 012.

58. Magill RA, Hall KG. A review of the contextual interference effect in motor skill acquisition. Hum Mov Sci. 1990;9:241-89.

59. Sanli EA, Patterson JT, Bray SR, Lee TD. Understanding selfcontrolled motor learning protocols through the self-determination theory. Front Psychol. 2013;11(3):611-28. https://doi.org/ 10.3389/fpsyg.2012.00611.

60. Wulf G, Lewthwaite R. Optimizing performance through intrinsic motivation and attention for learning: the OPTIMAL theory of motor learning. Psychon Bull Rev. 2016;23:1382-414. https://doi.org/10.3758/s13423-015-0999-9.

61. Masters RS, Poolton JM, Maxwell JP, Raab M. Implicit motor learning and complex decision making in time-constrained environments. J Mot Behav. 2008. 40:71-9.39.

62. Kinrade NP, Jackson RC, Ashford KJ. Reinvestment, task complexity and decision making under pressure in basketball. Psychol Sport Exerc. 2015;20:11-9.

63. Beilock SL, Carr TH. On the fragility of skilled performance: what governs choking under pressure? J Exp Psychol Gen. 2001;130:701-25.

64. Hardy L, Mullen R, Jones G. Knowledge and conscious control of motor actions under stress. Br J Psychol. 1996;87:621-36.
65. Masters RSW. Knowledge, "'knerves", and know-how: the role of explicit versus implicit knowledge in the breakdown of a complex motor skill under pressure. Br J Psych. 1992;83:343-58.

66. Masters R, Poolton J, Maxwell J. Stable implicit motor processes despite aerobic locomotor fatigue. Conscious Cogn. 2008; 17:335-8.

67. Poolton J, Masters R, Maxwell J. Passing thoughts on the evolutionary stability of implicit motor behaviour: performance retention under physiological fatigue. Conscious Cogn. 2007;16:456-68.

68. Winkelman N. The language of coaching - the art \& science of teaching movement. 1st edn. Human Kinetics Publishers; 2020.

69. Porter JM, Nolan RP, Ostrowski EJ, Wulf G. Directing attention externally enhances agility performance: a qualitative and quantitative analysis of the efficacy of using verbal instructions to focus attention. Front Psychol. 2010;29(1):216. https://doi. org/10.3389/fpsyg.2010.00216.

70. Eitam B, Kennedy PM, Tory HE. Motivation from control. Exp Brain Res. 2013;229:475-84. https://doi.org/10.1007/ s00221-012-3370-7.

71. Rosenqvist O, Skans ON. Confidence enhanced performance?The causal effects of success on future performance in professional golf tournaments. J Econ Behav Org. 2015;117:281-95.

72. Su Y, Reeve J. A meta-analysis of the effectiveness of intervention programmes designed to support autonomy. Educ Psychol Rev. 2011;23:159-88.

73. Brophy RH, Stepan JG, Silvers HJ, Mandelbaum BR. Defending puts the anterior cruciate ligament at risk during soccer: a gender-based analysis. Sports Health. 2015;7:244-9. https://doi. org/10.1177/1941738114535184.

74. Della Villa F, Buckthorpe M, Grassi A, Nabiuzzi A, Tosarelli F, Zaffagnini S, Della VS. Systematic video analysis of ACL injuries in professional male football (soccer): injury mechanisms, situational patterns and biomechanics study on 134 consecutive cases. Br J Sports Med. 2020;54:1423-32. https://doi.org/10. 1136/bjsports-2019-101247.

75. Grassi A, Smiley SP, Roberti di Sarsina T, Signorelli C, Marcheggiani Muccioli GM, Bondi A, Romagnoli M, Agostini A, Zaffagnini S. Mechanisms and situations of anterior cruciate ligament injuries in professional male soccer players: a YouTube-based video analysis. Eur J Orthop Surg Traumatol. 2017; 27:967-981. https://doi.org/10.1007/s00590-017-1905-0.

76. Waldén M, Krosshaug T, Bjørneboe J, Andersen TE, Faul O, Hägglund $\mathrm{M}$. Three distinct mechanisms predominate in noncontact anterior cruciate ligament injuries in male professional football players: a systematic video analysis of 39 cases. Br J Sports Med. 2015;49:1452-60. https://doi.org/10.1136/bjspo rts-2014-094573.

77. Shea JB, Morgan RL. Contextual interference effects on the acquisition, retention, and transfer of a motor skill. J Exp Psychol Hum Learn Mem. 1979;5:179-87. https://doi.org/10.1037/ 0278-7393.5.2.179.

78. Wymbs NF, Grafton ST. Neural substrates of practice structure that support future off-line learning. J Neurophysiol. 2009;102:2462-76. https://doi.org/10.1152/jn.00315.2009.

79. Henz D, Schöllhorn WI. Differential training facilitates early consolidation in motor learning. Front Behav Neurosci. 2016;21:199. https://doi.org/10.3389/fnbeh.2016.00199.

80. Mohammadi Orangi B, Yaali R, Bahram A, Aghdasi MT, van der Kamp J, Vanrenterghem J, Jones PA. Motor learning methods that induce high practice variability reduce kinematic and kinetic risk factors of non-contact ACL injury. Hum Mov Sci. 2021;78: 102805. https://doi.org/10.1016/j.humov.2021.102805. 